\title{
Investigating the Correlation Between Students' Reading Fluency and Comprehension
}

\author{
Tadiwos Hambamo Makebo \\ Department of English Language and Literature, Wolaita Sodo University, Ethiopia \\ Mebratu Mulatu Bachore \\ Hawassa University, Ethiopia \\ Zeleke Arficho Ayele \\ Hawassa University, Ethiopia
}

\begin{abstract}
The purpose of this research was to investigate the relationship between students' reading fluency and comprehension. It is a correlational design. A purposive sampling technique was employed to select the district, school, students, and grade level. Accordingly, 100 students participated in the study. As the research was quantitative, reading comprehension tests and comprehension-based silent reading fluency tests were applied to collect data. The data was analyzed using statistical techniques like Pearson product-moment correlation and linear regression. The findings revealed that reading accuracy level and reading rate, which are the parameters of reading fluency, were strongly correlated $(r=.885, P<0.01)$ with each other. However, silent reading fluency (SRF) had a moderate correlation with reading comprehension. Moreover, the reading rate had a strong positive correlation with reading accuracy $(r=.885, p<0.01$, and reading comprehension $(r$ $=.410, p<0.01)$. In addition, the linear regression outputs confirmed that the higher the students' reading rate and accuracy level, the higher their reading comprehension (Beta $=0.42, t=4.53, p<0.05)$. It means that when reading rate and accuracy increase, so do their reading comprehension. The results suggest that reading rate and accuracy levels are valid measures of reading ability when students read silently with comprehension
\end{abstract}

Index Terms — silent reading fluency, reading rate, reading accuracy, reading comprehension

\section{INTRODUCTION}

Many scholars agree that reading is that the most significant skill that learners got to achieve success within the academic environment. That's why UNESCO (2010) underscores that the pliability to read and extract meaning from text is also a fundamental skill necessary for several types of personal learning, intellectual growth, and academic attainment (Kwiatkowska-White, 2012). The center of reading is the ability to grasp and answer ideas expressed in writing (Nichols, Rupley, \& Blair, 2005). Lack of successful word recognition accuracy and automaticity is significant impediment for processing to a level of reading for meaning and learning. Readers who skirmish with words recognition have effort moving to the aim of speed reading and fluency in their reading; that permits them to think about comprehension of what they are reading (Valencia \& Buly, 2004; Rasinski, 2010). Students who lack adequate rehearsal in reading are doubtful to develop atomicity in word recognition (Rasinski, 2010).

At least two cognitive tasks are crucial in reading: attention to and competing for word recognition and comprehension. The more attention readers give to identifying words, the less attention they leave to administer reading comprehension (Foorman \& Metha, 2002; Samuels, 2002). Fluency serves as a bridge between word credit and understanding. Fluent readers can focus most of their attention on reading comprehension since they can identify words accurately and automatically. In addition, they can make connections between ideas in texts, between texts, and between their previous knowledge. Consequently, this study focused on comprehension-based silent reading fluency. Researchers and language experts relegated the nature of silent reading fluency and its guiding strategy to secondary school status relative to oral reading.

Ultimately, silent reading is most important in the tasks of colleges, workplaces, and communities, such as voting, reviewing documents to purchase large ticket items such as cars and houses, and seeking employment (Hiebert, 2015). Further, evaluators of silent reading based on students' reading proficiencies and national and international assessments. Silent reading is the mode of proficient reading. The present research is based on a theoretical framework by the National Reading Panel (NICHD, 2000) and emerging research on the relationship between silent reading comprehension and reading rate and is labeled as the Comprehension-Based Silent Reading Rate (CBSRR) (Spichting et al., 2016). Thus, this research lies in the CBSRR model.

Kim et al. (2010) argue that the verbal efficiency theory and the automaticity theory articulate the importance of reading fluency to reading comprehension. According to these theories, fast and accurate word reading and cognitive resources can be released for meaning construction and facilitate reading comprehension. Fluency improvement 
includes making excellent use of what is already known. The best development of fluency is speed-reading, where students focus on improving reading speed while maintaining good comprehension skills (Nation, 2009). For the advancement of reading fluency, stockholders should prepare textbooks judiciously to work well with EFL students; the reading materials need to be well within the students' level of proficiency. There should be little or no unknown vocabulary or grammatical features in texts prepared for fluency development purposes (Huffman,2021).

Moreover, when learners sit for a written test as part of an academic study, they write under time pressure. These four constituents of a language course: meaning-focused input, meaning-focused output, language-focused learning, and fluency development, ought to take up roughly equal time. Researchers conducted some large-scale and classroombased studies at the elementary grade levels over the last three decades and discovered that instruction in reading fluency leads to improvements in reading comprehension. Moreover, it improved the overall reading proficiency levels (Rasinski et al., 2014). Although the researchers acknowledged the importance of reading fluency within the early grades, there have been a limited number of studies at the secondary levels, which has led to the necessity to conduct further studies within the area. In Ethiopia, studies have consistently revealed that primary and secondary school students have serious problems and lack basic skills in reading the language (English), which is taken as a tool of science and technology (Early Grade Reading Assessment, 2018, Ministry of education in Ethiopian, 2013).

According to the findings of the above studies, secondary school students tend to have little motivation, interest, and commitment to their education. The studies reported that students did not possess adequate reading skills to continue their secondary and higher education (Ministry of education, 2018). For example, in 2015, half of grade four and eight students scored below the basic reading proficiency level for all subjects. Specifically, about $44 \%$ of grade 4 students tested nationally were below the basic level in reading (Early Grade Reading Assessment, 2018). Moreover, Deribe (2019) points out that the reading ability of Ethiopian students has been declining. Furthermore, Bizuwork (2018) underlines that students' reading comprehension performance was low because they lack basic reading comprehension skills in English.

As a teacher of English, the researcher observed that students were making slow progress in learning to read. On the other hand, many of the students had excellent vocabulary; they knew the meanings of many words; others controlled the examination with few mistakes in word recognition; still others demonstrated high levels of comprehension. The most commonly observed reading problem in high school students, however, is slow or inefficient reading. Sluggish reading may necessitate a significantly longer time in the reading task than reading with appropriate peace, and the current study sought to investigate the extent of the accuracy of this observation. In Ethiopian secondary school contexts, the contribution of students' reading fluency to their reading comprehension is not examined. Therefore, the current study, to the researchers' knowledge, is the first of its kind to examine the relationship between students' reading fluency and their reading comprehension at the Ethiopian high school level, where students have ample time for selfstudy.

The current study aimed to investigate the relationships between students' reading fluency and their reading comprehension. Specifically, it attempted

1. To examine the relationship between students' reading rates, accuracy, and comprehension

2. To see the contributions of students' reading fluency to their reading comprehension,

3. To examine the extent to which students' reading fluency predicts their reading comprehension.

\section{REVIEW OF RELATED LITERATURE}

Fluency is a student's ability to have clear meaning from reading comprehension, no hesitation throughout reading the given texts, and appropriate speed of delivery. Instead, ministry of education (2003) defines accuracy as using correct vocabulary, grammar, pronunciation, and a suitable level of formality. The Grade 11 English for Ethiopia teacher's guide and student textbook strongly suggest that teachers should get the students to bring in their favorite reading materials (a novel or short story) and share them with their classmates. It also suggests teachers give attention to students' reading fluency. The average reading rate of students in grade 11 is expected to be between 250 and 300 wpm in silent reading (Rasinski, 2006). Researchers began to use fluency as a synonym for automated processing, distinguishing between verbal and silent reading. They observed that students first mastered reading aloud and then moved on to silent reading (Paige, Rasinski, Lavell, Smith, 2014). That transition typically happens at the end of the elementary grade, immediately through a developmental shift from learning to read to reading to learn (Nation, 2009). Silent reading has the advantage of not being limited by the speed limit of speech generation. This requires additional resources other than silent word recognition for experienced readers (Schreiber, 1980).

In addition, La Berge and Samuels (1974) introduced the concept of automaticity. They claim that reading a word automatically uses less cognitive resources. Reading comprehension reallocates intellectual resources that require more cognitive resources (Berninger, Abbott, Olson, Gould, Hiramatsu, Holsinger, McShane, Murphy, Norton, Boyd, Westhaggen, 2010). Thus, experts associate automatic word reading with reading comprehension. Fluency has a contribution to the field of Cognitive Psychology. Schneider and Shiffirin (2003) introduced a cognitive study of written word processing that distinguishes between controlled strategic processing that requires conscious attention and automated processing that does not require conscious attention. Researchers have shown that students use conscious and controlled strategic reading processes when learning new words (Berninger et al., 2010). However, they practiced their 
skills to master the language; they may switch from controlled strategies to automatic pilots. Their recent research shows that, although automatic processing tends to be fast, initially slow, conscious, and controlled strategic processing may be practiced, and become very fast, but not necessarily automatic(Paige et al. 2014). Current cognitive research on reading has moved beyond spontaneous and controlled processing to research on flexibility. Skilled readers can flexibly apply many knowledge sources and strategies and know when to automatize and when to engage in reflection (Cartwright, 2008, Samuels, 1987). It also has a contribution to the field of special education. Deno (1985) introduced the Curriculum-based Measure (CBM) as an alternative to psychometric test measures.

Curriculum-based measures are timed tasks used to assess students' responses to the reading curriculum. CBM typically measures accurate performance within a constant time limit (1 minute) at a constant rate (number of seconds per word) or speed (words per minute) (Jenkins et al., 2003). CBM is time-related and is frequently used in the assessment of reading fluency Silent reading dominated the reading of adults in the context of college, careers, and communities(Jenkins, Schulze, Marti, Harbaugh,2017). The National Center for Education Statistics (2017) focuses on offering instructional experiences to students to be proficient in reading more insights into patterns of silent reading (Hiebert, 2019). The present research built on a theoretical framework and an emerging body of research on the link between comprehension and rate in silent reading (Spichtig et al., 2016, Hiebert \& Trainin, 2019). It focused on getting meaning during real-time readings. At the high school level and higher (Hiebert, Samuels, \& Rasinski, 2019). It is an efficient way of getting meaning while reading and it is crucial to gain connotations efficiently from the text in all academic works. Besides, it is vital that rate-based measures are valuable in progress monitoring because they are more sensitive to growth than accuracy-based measures. The rate of reading with comprehension is a good measure of general reading ability.

Some researchers have conducted studies on silent reading. For example, Huey (1908) studied the automaticity of silent reading. The research done by Carver (in the 1960s and '90s) showed that an optimum reading rate with maximum comprehension efficiency was possible. The National Reading Panel (2000) says fluency is significant in the inclusion of fluency training in schools. Generally, the availability of eye-tracking technology has accelerated the amount of research on the silent reading rate in the past 15-20 years. This research engrossed on fluency and reading comprehension because students are considered proficient readers when reading fluency and reading comprehension are at grade level. Eventually, it can fill the gap left by studies dedicated only to oral reading fluency, which is limited to the elementary school level. In comprehension-based silent reading fluency, students most often conduct reading tasks silently on their own for a sustained period in high school, the community, and the workplace.

\section{MATERIALS AND MeTHODS}

The present research mainly relied on a correlational research design. Thus, this helped to see the relationship between the two variables: reading comprehension and fluency, using the appropriate statistical output for interpretation.

\section{A. Research Setting}

The researchers conducted this study in an Ethiopian EFL context in the 2020-2021 academic year. It focused on examining the relationships between comprehension-based silent reading fluency and reading comprehension with reference to grade 11 students in selected schools in Wolaita Zone, Sodo Town, South Ethiopia. From this zone, the researchers purposively selected four general secondary schools, since they are better resourced and have better libraries, and the town has advanced public libraries. The researchers anticipated that these might motivate students to engage in reading tasks and build autonomous reading abilities.

\section{B. Participants}

This research targeted Grade 11 students at four secondary schools in the Wolaita Zone, located in South Ethiopia. The selection of the schools and grade levels was purposeful. The researchers believed that grade 11 students could take responsibility for their learning of the language through reading. To determine the sample size, the researchers applied Morgan and Krejice (1970) techniques. These researchers created a table to determine the sample size for a specific defined population without the need for any calculations (Cohen, Manion, \& Marrison 2007: p.107 as cited in Tekele 2016). Based on the idea of Table 1, as the population increases, the sample length will increase at a diminishing rate and stay surprisingly consistent at barely greater than 380 cases The formula used to construct it was $\mathrm{S}=\mathrm{X} 2 \mathrm{NP}(1-\mathrm{P}) \mathrm{d} 2$ $(\mathrm{N}-1)+\mathrm{X} 2 \mathrm{P}(1-\mathrm{p})$. In which $\mathrm{S}=$ required sample size, $\mathrm{X} 2=$ table value of chi-square for 1 degree of freedom at the desired confidence level (3.841. $\mathrm{N}=$ the population size, the population proportion (assumed to be.50 because this will offer the most sample size) and $d=$ the degree of accuracy expressed as a proportion (.05) (Krejicie \& Morgan, 1970: p.607 as cited in Oguttu 2015). In the 2020-2021 academic year, the 11th grade students of the schools surveyed was 140. Therefore, a sample of 100 students was extracted to represent the population. This procedure provided a sample size distribution large enough to manage the selected tools. Researchers selected subjects by lottery using a simple random sample. 
TABLE1

DETERMINING SAMPLE SIZE FROM A GIVEN POPULATIONS

\begin{tabular}{|c|c|c|c|c|c|}
\hline $\mathrm{N}$ & S & $\mathrm{N}$ & $S$ & $\mathrm{~N}$ & $\mathrm{~S}$ \\
\hline 10 & 10 & 220 & 140 & 1200 & 291 \\
\hline 15 & 14 & 230 & 144 & 1300 & 297 \\
\hline 20 & 19 & 240 & 148 & 1400 & 302 \\
\hline 25 & 24 & 250 & 152 & 1500 & 306 \\
\hline 30 & 28 & 260 & 155 & 1600 & 310 \\
\hline 35 & 32 & 270 & 159 & 1700 & 313 \\
\hline 40 & 36 & 280 & 162 & 1800 & 317 \\
\hline 45 & 40 & 290 & 165 & 1900 & 320 \\
\hline 50 & 44 & 300 & 169 & 2000 & 322 \\
\hline 55 & 48 & 320 & 175 & 2200 & 327 \\
\hline 60 & 52 & 340 & 181 & 2400 & 331 \\
\hline 65 & 56 & 360 & 186 & 2600 & 335 \\
\hline 70 & 59 & 380 & 191 & 2800 & 338 \\
\hline 75 & 63 & 400 & 196 & 3000 & 341 \\
\hline 80 & 66 & 420 & 201 & 3500 & 346 \\
\hline 85 & 70 & 440 & 205 & 4000 & 351 \\
\hline 90 & 73 & 460 & 210 & 4500 & 354 \\
\hline 95 & 76 & 480 & 214 & 5000 & 357 \\
\hline 100 & 80 & 500 & 217 & 6000 & 361 \\
\hline 110 & 86 & 550 & 226 & 7000 & 364 \\
\hline 120 & 92 & 600 & 234 & 8000 & 367 \\
\hline 130 & 97 & 650 & 242 & 9000 & 368 \\
\hline 140 & 103 & 700 & 248 & 10000 & 370 \\
\hline 150 & 108 & 750 & 254 & 15000 & 375 \\
\hline 160 & 113 & 800 & 260 & 20000 & 377 \\
\hline 170 & 118 & 850 & 265 & 30000 & 379 \\
\hline 180 & 123 & 900 & 269 & 40000 & 380 \\
\hline 190 & 127 & 950 & 274 & 50000 & 381 \\
\hline 200 & 132 & 1000 & 287 & 75000 & 382 \\
\hline 210 & 136 & 1100 & 285 & 1000000 & 384 \\
\hline
\end{tabular}

\section{Instruments}

The study employed reading comprehension tests and comprehension-based silent reading fluency tests as instruments of data collection. The reading comprehension and CBSR tests were employed to examine the relationship between students' reading comprehension and comprehension-based silent reading fluency. A 40-item reading comprehension test was applied using true/false, matching headings questions, matching vocabulary meanings in context, and multiple-choice questions. As the purpose of this test was to assess general reading proficiency, the researchers employed the reading proficiency criteria to examine grade 11 students' expected reading standards. In addition, the researcher applied a standardized test adapted from Cambridge Preparation for the TOEFL online test (2014: p. 26) that measures students' reading comprehension skills.

As a complement, the Flesch-Kincaid readability formula was chosen to evaluate the reading complexity of the reading comprehension test. It was fixed in Microsoft Word's spelling and grammar was easily calculated. To enable the readability statistics, the researcher used MS Office Word 2010 in this study. Flesch-Kincaid Grade Level $=0.39$ x ASL + 11.8 x ASW -15.59. ASL = average sentence length (number of words divided by the number of sentences) (Asad, 2017). ASW = average number of syllables per word (the number of syllables divided by the number of words) (DuBay, 2006). Grounded in Flesch-Kincaid, the text was analyzed using the number of words, sentences, and syllables in the text. Additionally, the researcher checked the reliability of the reading comprehension test. A frequently used version of the K-21 formula was as follows: Where $\mathrm{K}$ is the number of items on the test, $\mathrm{M}$ is the mean of the set of test scores, and SD is the standard deviation of the test scores (Irawan 2013). Therefore, the statistics of frequency are as follows.

TABLE 2

PRE-PILOT STUdy READING COMPREHENSION TEST DESCRIPTIVE STATISTICS

\begin{tabular}{ll}
\hline Descriptive Statistics & Value \\
\hline Mean & 32.44 \\
Std. Deviation & 11.649 \\
\hline
\end{tabular}

As shown in Table 2 above, the number of cases valid is $50 \&$ the numbers of items is 40 . Further, the mean and standard deviation scores on the same test are 32.44 and 11.649 consistently. There were no missing values. From the table, it is possible to calculate the reliability of the reading comprehension test. $\frac{\mathrm{k}}{\mathrm{k}-1}$ 圆 $1-\frac{\mathrm{MEK}-\mathrm{M})}{\mathrm{K}\left(\mathrm{SD}^{2}\right)} \mathrm{K}=40 \mathrm{M}=32.44$ 
$\mathrm{SD}=11.649=\frac{40}{40-1}$ 圆 $1-\frac{32.44(7.56)}{40\left(11.649^{2}\right)}$ 圆 $=\frac{40}{39}$ 目 1 - $\frac{32.44(40-32.44)}{40(135.699201)}=\frac{40}{39}$ 目 $\left.1-\frac{245.2464)}{5427.96804}\right]=1.0256410(1-$ $0.04518199)=(1.0256410)(0.954818009) \quad=0.98$ Thus, there is strong internal consistency for the test in the way that participants responded to multiple items on the scale of the reading comprehension

In addition, the researchers adapted a reading fluency test to the aims of the web plus silent reading fluency, which measures the rate of reading grade-level text with comprehension. Its content consists of texts (stories) written and administered on the screen. The researchers informed the students to be ready to read from the screen at a given time, and they answered the multiple-choice questions without looking back at the screen. The reading text was broken into sediments with a question following each segment. The text was written at grade level using reading maturity matrices. In this study, 100 eleventh-grade students were asked to read a 574-word text divided into eight sections. They read a text about Indian marriage in a group setting where the observer recorded the time. Immediately after reading each section, students answered the four-choice comprehension questions (Heibert \& Daniel, 2019).

The text was divided into eight segments of 47 to 100 words, and each segment was followed by comprehension questions. The segment was to reduce memory demands and increase the number of independent rate measurements. Directions were given, followed by instructions to work quickly but carefully since students had not looked back at the text when answering the questions. After reading each segment, the observer clicked the next button and saw a new screen with the option questions about the segment. Questions were designed to see whether students understood the gist (Heibert \& Daniel, 2019). The rating score for the text was median WPM, and students were likely to answer seven out of ten (75\%) questions correctly. Tolerant responses account for 75\% of correct answers (Pearson, 2015). The test was as quick and easy to use as possible. Time given to assessment was usually taken away from instruction. Fluency has three levels: word level, sentence level, and passage level. The researchers tested the students with measures of comprehension based on silent reading fluency. Administering the comprehension-based silent reading was to measure the rate of reading at grade level text and computer-administered. It is reliable, valid, and sensitive to growth. Therefore, the researcher determined the level of students' reading by the percentage of words a reader had read correctly (Fuchs, Fuchs, \& Deno, 1982, as cited in Rasinski, 2004).

Flesch-Kincaid, Grade Level was used to test the readability rate of the texts. The Flesch-Kincaid readability tests indicate how difficult a passage in English is to grasp (Flesch, 2006). The researchers had two common reasons for measuring readability: to develop the instrument (reading passage) and to apply the language. Readability, as it is practical in document design, is concerned with such matters as sentence line length, white space, font type, and the like. Readability as applied to language is concerned with the understandability of a piece of written text (Sutopo, 2019). It is crucial because it goes to the very heart of our professional ethics. Therefore, the researchers used MSW (Microsoft Word 2010) to calculate the readability statistics for the reading passage. In which case the numbers that MSW generates automatically with the word count. The Flesch-reading ease test scores out of $100 \%$ based on its readability. The reading test has a score of 58.9. Flesch-reading ease and Flesch-Kincaid grade level 9.0. A mark of 50-70 means that the content is at the right level for 9th grade or above grade reading level. The table below shows the interpreted scores.

TABLE 3

FLESCH-KINCAID EQUATION MICROSOFT READABILITY PROGRAM

\begin{tabular}{llll}
\multicolumn{4}{c}{ FLESCH-KINCAID EQUATION MICROSOFT READABILITY PROGRAM } \\
\hline & Score & Notes & Grade level \\
\hline 1 & $90.0-100.0$ & Easily understood by an average of 11 year- old students & $7^{\text {th }}-8$ th \\
2 & $60.0-78.0$ & Easily understood by an average of 13 to 18 year- old & $9^{\text {th }}-10^{\text {th }}$ \\
3 & 00.30 .0 & Best understood by above 19 year- old & $11^{\text {th }}-12^{\text {th }}$ \\
\hline
\end{tabular}

According to Nation (2005), readers should score at least seven out of ten on a comprehension test for careful silent reading. Note, learners should decrease their reading speed and read more texts at a similar level until they improve their reading (p.131-44). Floencio (2004) explained the effects of time controls on comprehension with secondary school and college students under three conditions: one, no pressure (90wpm), next, mild time pressure (130wpm), and last, severe time pressure (300 wpm)( Modern Journal of Language Teaching Methods (2011). Gordon (2007) strongly suggests that reading rate and comprehension are not two separate elements in the reading process. Reading rate refers to the speed of reading comprehension. To measure the effective reading rate of EFL students, Gordon (2007, P.34) suggested the following calculation: reading rate = reading speed (words per minute) x questions square divided by 100 .

TABLE 4

MEASURING READING RATE IN TERMS OF CORRECT RESPONSES ON THE COMPREHENSION TEST (DODI, 2013)

\begin{tabular}{llll}
\hline R.N & Reader & Rate (wpm) & Comprehension \\
\hline 1 & Poor & $10-100$ & $30-50 \%$ \\
2 & Average & $200-240$ & $50-70 \%$ \\
3 & Functionally Literate & 400 & $70-80 \%$ \\
4 & Top in 100 & $800-1000$ & $80 \%+$ \\
5 & Top in 1000 & $1000+$ & $80 \%+$ \\
\hline
\end{tabular}

(Source: Adapted from Gordon Wainwright, 2007) 
Based on the Table 4, this study attempted to come up with sound conclusions based on valid data collected through appropriate instruments. Consequently, the trustworthiness of the deductions of a research study refers to its validity. In other words, legitimacy relates to whether research has achieved what it has set out to achieve (Kumar, 2006). It implies the extent to which a study captures the true meaning of the issue under investigation as a function of its validity. On the other hand, the findings of a study should be reliable to replicate with consistent results under similar conditions. The magnitude to which research is pretended was verified using similar procedures to produce consistent results at different times; circumstances refer to its reliability. Therefore, validity and reliability are vital to research concepts (Tekele, 2016).

\section{Methods of Data Analysis}

The researchers of the present study assessed the relationships of the variables using different statistics. Correlation coefficients are employed with data depending on the level of measurement on which each variable has measured the nature of the underlying distribution (continuous variables) the characteristics of distribution (linear)(Rudolf, William \& Ping,2006). Pearson product-moment association coefficient(r) is employed with like Likert scale as scaled test variables and reading tests as ratio variable. Besides, the researchers also used linear regression. The correlation was concerned with the magnitude and direction of the relationship. However, regression is a statistical method used to determine the strength and characteristics of the relationship between the dependent and independent variables. Using the data of correlation, the researcher came up with a regression equation for acting the prediction. In regression, researchers use the relationship between two variables to predict the value of one of the other variables.

\section{FINDINGS AND DISCUSSIONS}

\section{A. Results of Reading Fluency Measures}

The data of fluency measures (accuracy and rate) were analyzed using SPSS version 21 to see the association with reading grasp. The next table proves the results of the numerical analysis.

TABLE 5

Results of StatisticAl ANALysis Of READING COMPREHENSION TEST, COMPREHENSION BASED SILENT READING ACCURACY LEVEL AND READING RATE

\begin{tabular}{lllllll}
\hline & & Participants(N) & Mean(X) & Median & Mode & Std. dv \\
\hline 1 & Reading accuracy & 100 & 35.5 & 30 & 30 & 12.3 \\
2 & Reading rate & 100 & 87 & 75 & 75 & 30.9 \\
3 & Reading Comp. & 100 & 37.58 & 35 & 33 & 13.08 \\
\hline
\end{tabular}

Table 5 above depicts the output of the data. The mean, median, and mode of accuracy levels are 35.50, 30, and 30 correspondingly. These three measures of central values are in close agreement, indicating that the middle of the distribution happens to be the midpoint of the comprehension-based silent reading accuracy level. The standard deviation of the reading comprehension test (13.08) indicates the variability of the comprehension test on average of about two points from the mean. Measures of the central tendency of reading rate show that mean, median, and mode $(87,75,75$.$) . This statistical output does provide some initial evidence that accuracy level and reading rate are$ significant; there was no much change in the standard deviation of reading rate. The standard deviation of the reading rate was 30.87 which shows a variability level on reading speed on average about two and a half points from the mean.

TABLE 6

FREQUENCY TABLE OF ACCURACY LEVEL OF COMPREHENSION BASED SILENT READING

\begin{tabular}{llll}
\hline R.N & Range of accuracy & frequency & percent \\
\hline 1 & $10-30$ & 60 & $60 \%$ \\
2 & $31-50$ & 30 & $30 \%$ \\
3 & $51-70$ & 10 & $10 \%$ \\
4 & $71-90$ & - & - \\
5 & $91-100$ & - & $100 \%$ \\
6
\end{tabular}

Examination of the frequency table of accuracy level (Table 6) approves that the highest frequency score on reading test accuracy level was between 51-- 70 (10 students, or 10\% of students attain adequate level of correct responses y, $90 \%$ of students did not attain an adequate level of correct responses on the comprehension test. Students' score is expected $75 \%$ accuracy at reading the text segments (words per minute.) 
TABLE 7

FREQUANCY TABLE OF THE READING RATE OF COMPREHENSION BASEd SILENT READING

\begin{tabular}{llll}
\hline R. No & Reading rate & frequency & percent \\
\hline 1 & $25-50$ & 17 & 17 \\
2 & $75-100$ & 67 & 67 \\
3 & $101-125$ & 5 & 5 \\
4 & $150-175$ & 11 & 11 \\
5 & Total & 100 & 100 \\
\hline
\end{tabular}

Table 7 depicts that $17 \%$ reading rate of grade 11 students is in a range between $25-50$ words per minute. During this reading, the construction of meaning occurs while students are reading. The rating score based on time spent on reading the text is conditional on comprehension (Hiebert et al., 2018). In addition, the data presented from a study of comprehension-based silent reading rates $67 \%$ of students ranged from 75-100 words per minute silently with comprehension. Only $16 \%$ of students read at a rate ranging between 101-175 WPM of comprehension-based silent reading. There was a deprived relationship between the rate at which readers recognized words in reading and their construction of meaning. The backgrounds and causes for students' patterns of underprivileged comprehension need additional investigation. The table also depicts $15 \%$ of the students were average readers.

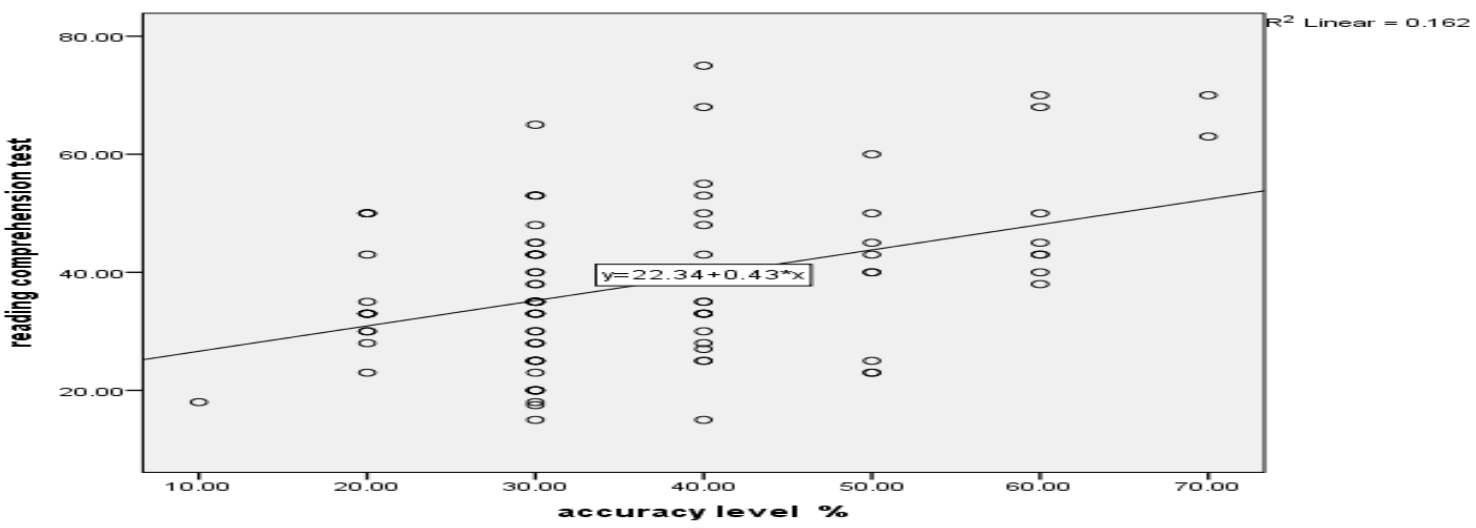

Figure 1: Scatter Plot: Accuracy Level with Reading Comprehension

In the scatter plot Figure 1 above, the horizontal axis displays students reading accuracy levels; the vertical axis shows comprehension test scores. Each dot on the scatter plot represents students' responses from the data set. The location of each point on the graph depends on both reading accuracy and comprehension test scores. Students with higher accuracy level scores are located further to the right, and students with higher comprehension test scores are situated higher up on the graph. For example, only two students answered 70 correctly out of 100 that is $70 \%$ accurately Thus, these students are less accurate, and they are using much effort to achieve optimal comprehension and reading at a frustration level. Only two students attained 70 and 1 student 75 out of 100 on the reading comprehension test.

The scatter plot also confirms that there is a moderate increase in students reading comprehension scores as the reading accuracy increases. Its relationship was linear. In addition, the square of the correlation coefficient (R2) was 0.162. The proportion of the variation in the reading comprehension test is accounted for by the variation inaccuracy level. The percentage of the variation in reading comprehension explained by students' accuracy level (R 2 is 0.162$)$ is 16.2 percentages. When its value ranges from zero to one, it is in ratio form. $\mathrm{R}^{2}$ close to zero shows no linear relationship, whereas a value close to one shows a perfect linear fit.

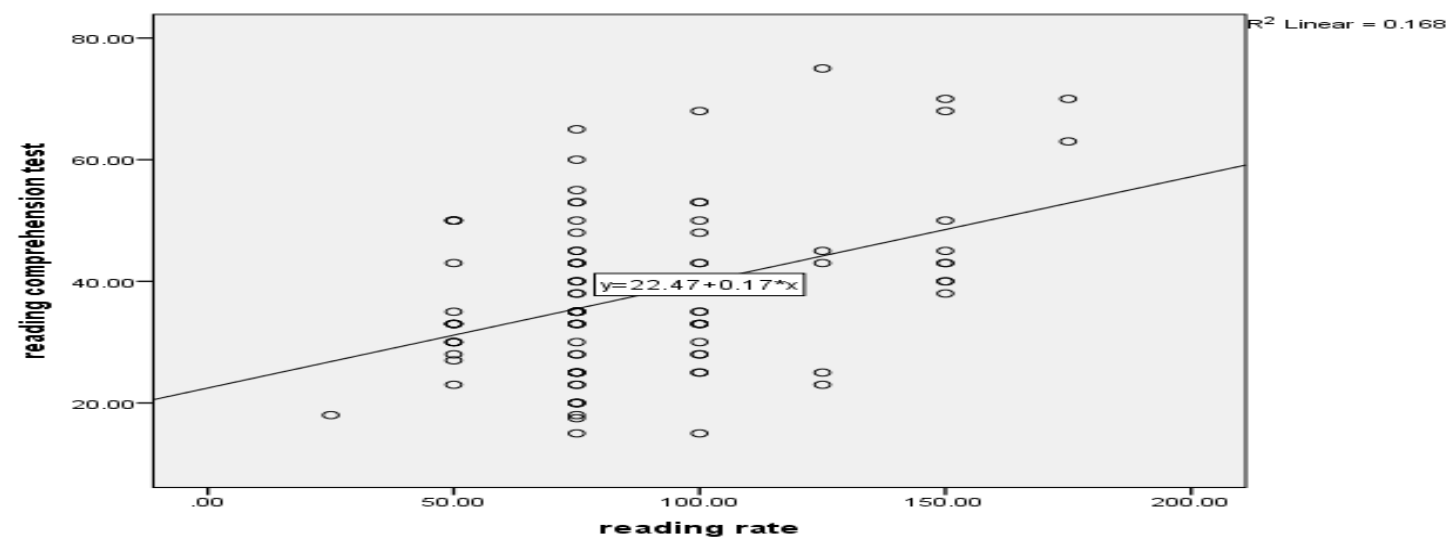

Figure 2: Students Reading Comprehension Test Score and Reading Rate 
The scatter plot shown in Figure 2 above depicts a moderate increase in students reading comprehension scores as the reading rate increases. Its relationship is linear. The location of each point on the graph depends on both reading rate and comprehension test scores. Students with higher reading rates are located further to the right; comprehension test scores are set higher up on the graph. For example, only two students' reading rate is 175 words per minute (wpm). Taylor rated e students to read 234 WPM at grade 11 level, which is grade equivalent. As per Table 7, grade equivalents for rates in standard-length words per minute these students are about grade 7 level reading ability.

B. Relationship between Rate, Fluency and Comprehension

TABLE 8

PEARSON PRODUCT-MOMENT CORRELATION COEFFICIENT

\begin{tabular}{|c|c|c|c|c|c|}
\hline R.no & & & accuracy level & reading rate & $\begin{array}{l}\text { comprehension } \\
\text { test }\end{array}$ \\
\hline \multirow[t]{3}{*}{1} & accuracy level \% & Pearson Correlation & 1 & $.885^{* * *}$ & $.402^{* *}$ \\
\hline & & Sig. (2-tailed) & & .000 & .000 \\
\hline & & $\mathrm{N}$ & 100 & 100 & 100 \\
\hline \multirow[t]{3}{*}{2} & reading rate & Pearson Correlation & $.885^{* *}$ & 1 & $.410^{* *}$ \\
\hline & & Sig. (2-tailed) & .000 & & .000 \\
\hline & & $\mathrm{N}$ & 100 & 100 & 100 \\
\hline \multirow[t]{3}{*}{3} & comprehension test & Pearson Correlation & $.402^{* *}$ & $.410^{* *}$ & 1 \\
\hline & & Sig. (2-tailed) & .000 & .000 & \\
\hline & & $\mathrm{N}$ & 100 & 100 & 100 \\
\hline
\end{tabular}

**. Correlation is significant at the 0.01 level (2-tailed).

Table 8 portrays the correlation between reading comprehension test scores and reading fluency measures (accuracy and reading rate). Reading accuracy level and reading rate are correlated strongly $(\mathrm{r}=.885, \mathrm{P}<0.01)$. However, silent reading fluency (SRF) had a moderate correlation with the reading comprehension test. The reading rate and accuracy had a strong positive correlation $(r=.885, \mathrm{p}<0.01)$ with reading comprehension of $\mathrm{r}=.410$. These results suggest that silent reading rate and accuracy levels are valid measures of reading ability when students read silently with comprehension. When reading rate and accuracy increases, so do their reading comprehension. This interpretation in no way implies causality increases in reading fluency measures caused by increased reading comprehension. The significant relationship merely indicates that the two variables' covariance.

\section{The Degree of Reading Fluency to Predict Comprehension}

\section{Reading Accuracy}

The researchers of this study used simple linear regression to examine the relationship between students' comprehension-based silent reading fluency and their reading. The prediction used for Simple linear regression analysis produced regression equations. A statistical test performed regarding the slope $(\alpha)$ of the regression line was to evaluate how well a set of data fits a simple linear regression model. The hypothesis is as follows: H0: $\beta=$ zero (there is no linear relationship between students' comprehension-based silent reading accuracy level and reading comprehension) $\mathrm{H} 1$ : $\beta \# 0$ (there is a linear relationship between students' comprehension-based silent reading accuracy level and reading comprehension).

TABLE 9

LINEAR REGRESSION OUTPUT FOR ACCURACY LEVEL

\begin{tabular}{|c|c|c|c|c|c|c|c|c|c|c|}
\hline & & & & & \multicolumn{6}{|c|}{ Predictors: (Constant), reading accuracy Coefficients } \\
\hline & & & & & & \multicolumn{2}{|c|}{$\begin{array}{l}\text { Unstandardized } \\
\text { coefficients }\end{array}$} & \multicolumn{2}{|c|}{$\begin{array}{l}\text { Standardized } \\
\text { Coefficients }\end{array}$} & \\
\hline & R Square & $\begin{array}{l}\text { Adjusted } \\
\text { Square }\end{array}$ & $\mathrm{R}$ & Std. Error & & B & $\begin{array}{l}\text { Std. } \\
\text { error }\end{array}$ & B & & \\
\hline $\mathrm{R}$ & & & & & & & & & $\mathrm{t}$ & Sign \\
\hline \multirow[t]{2}{*}{$0.402^{\mathrm{a}}$} & 0.162 & 0.153 & & 12.04 & & 22.34 & 3.70 & & 6.02 & 0.00 \\
\hline & & & & & $\begin{array}{l}\text { Constant } \\
\text { Reading } \\
\text { Comp. }\end{array}$ & 0.42 & 0.09 & 0.402 & 4.34 & 0.00 \\
\hline
\end{tabular}

a. Dependent Variable: Reading Comprehension Test

To create a prediction equation the researchers used SPSS. So, the prediction equation is $Y^{\prime}=A+B X$, where $Y^{\prime}=$ the predicted dependent variable, $\mathrm{A}=\mathrm{Constant}, \mathrm{B}=$ un standardized regression coefficient, and $\mathrm{X}=\mathrm{value}$ of the predictor variable (Ho, 2006). To make this prediction, the researcher used the reading accuracy. The reading accuracy would be one independent variable (X) variable (Rudolf, William \& Ping, 2006). The relevant information for constructing a prediction equation has existed in the coefficient table (Table:9) (Cowan,1998).To predict the students reading comprehension scores from their reading accuracy level, the researcher used the value presented in the unstandardized coefficient column of Table 9. Using the constant and B (unstandardized coefficient) values, the prediction equation Y= 
0.429 reading comprehension test, $\mathrm{X}=22.340$ accuracy level. So, the equation $\mathrm{Y}=.429 * \mathrm{X}+22.34$. X represents the previous reading accuracy level.

Therefore, the researchers predicted for an accuracy level of (X) 99\%.Thus, $.429 \mathrm{x} 99+22.34=64.811$. The predicted result of the reading comprehension test scores the researchers expected from students whose reading accuracy of $99 \%$ would be 64.81 correct responses on the comprehension test from $100 \%$. A measure of the computed equation is Rsquare, sometimes called the coefficient of determination-square (Amulya, 2019). It is simply the square of multiple correlation coefficients listed under R- in the model summary table. Besides, it represents the proportion of variance accounted for in the dependent variable (reading comprehension). In simple regression, where there is only one predictor variable, the multiple $\mathrm{R}$ is equivalent to the simple $r$ (Pearson product-moment correlation)(San,2011). The coefficients for this are 0.402 , and the $\mathrm{R}$ square is 0.162 . Thus, in this sample, the predictor variable of reading accuracy level has explained $16.2 \%$ of the variance in the dependent variable of reading comprehension (Rudolf, William \& Ping, 2006). The coefficient table presents the standardized Beta coefficient between the predictor variable (reading accuracy level) and the dependent variable (students reading comprehension score). The Beta coefficient is positive and statistically significant at the 0.05 level. Thus, the higher the comprehension-based silent reading accuracy level, the higher their reading comprehension tests score, Beta $=0.402, \mathrm{t}=4.35, \mathrm{p}<0.05$. The standard coefficient of 0.402 is identical to the multiple regression coefficients.

\section{Reading Rate}

The researcher used simple linear regression to examine the relationship between one predictor (independent) variable - comprehension-based silent reading fluency measures (reading rate) and a single quantitative response (dependent variable) reading comprehension test in this study. Simple linear regression analysis produces regression equations for prediction. A simple linear regression model statistical test was performed regarding the slope $(\alpha)$ of the regression line to assess the appropriateness of data. The hypothesis is as follows:

$\mathrm{H} 0: \beta=0$ (there is no linear relationship between reading rate and comprehension

$\mathrm{H} 1: \beta \# 0$ (there is a linear relationship between reading rate and comprehension)

TABLE 10

READING RATE AND READING COMPREHENSION TEST

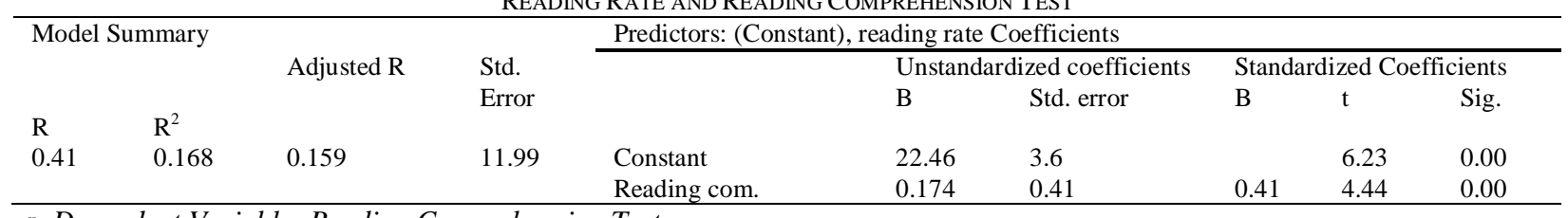

a. Dependent Variable: Reading Comprehension Test

To create a prediction equation the researchers used SPSS in order to predict a reading comprehension. So, the prediction equation is $\mathrm{Y}^{\prime}=\mathrm{A}+\mathrm{BX}$, where $\mathrm{Y}^{\prime}=$ the predicted dependent variable, $\mathrm{A}=\mathrm{C}$ onstant, $\mathrm{B}=$ un standardized regression coefficient, and $\mathrm{X}=$ value of the predictor variable (Rudolf, William \& Ping, 2006). To make this prediction, the researcher used the reading rate. The reading rate would be one independent variable (X) variable. The relevant information for constructing a prediction equation exists in the coefficient table (Table: 10).To predict the students reading comprehension scores from their reading rate, the researchers used the value presented in the unstandardized coefficient column (Rudolf, William \& Ping, 2006). Using constant and B (un standardized coefficient) values prediction equation (Rudolf, William \& Ping, 2006) would be $Y=0.174$ reading comprehension test, $X=22.466$ reading rate. So, the equation $\mathrm{Y}=.0 .174 * \mathrm{X}+22.466$. $\mathrm{X}$ represents the students' previous reading rate. Therefore, the researchers predicted for silent reading rate with comprehension of (X) 237wpm thus, $0.174 \times 237+22.466=63.704$. The projected result of students reading comprehension test scores the researcher expected from the students who have reading rate with comprehension of $237 \mathrm{wpm}$ would be 63.704 correct responses on the comprehension test out of 100 . A measure of the strength of the computed equation is R- square called the coefficient of determination. R-square is actually the square of the multiple correlation coefficients indexed under $\mathrm{R}$ in the model summary table. It represents the proportion of variance responsible for the dependent variable reading comprehension test by the predictor variable (Amulya, 2019). The multiple regressions is equivalent to the multiple R (Pearson product-moment correlation) (San, 2011). Thus, the multiple correlation coefficients are .410, and the R-square is .168. Thus, for this sample, the predictor variable reading rate has explained $16.8 \%$ of the variance in the dependent variable of reading comprehension test score.

\section{Discussion}

However, the construct of fluency might also were left out in the past (the neglected reading goal and was a critical variable for reading success, yet it is often ignored in reading curricula.) it is receiving plenty deserved interest presently. Rasinski, Nageldinger, and Paige (2015) for instance reported despite its importance, fluency continued to be miss understood, both in research and in practice. Supporting the same idea, Games, Jacob, Horest, and Unlu (2008) noticed that fluency continues to be neglected in reading classroom. Very robust studies and theoretical base shows that at the same time as fluency is not always sufficient to make sure excessive ranges of reading comprehension achievement, fluency is essential for that achievement, as it depends on and typically displays comprehension. Pikulski 
and Chard (2005) reported fluency as a bridge between word recognition accuracy and reading comprehension. Ming and Dukes (2008), stress fluency as an essential element of comprehensive reading in an inclusive classroom.

If a reader has no longer developed fluency, the process of interpreting words drains attention, and inadequate attention is available for building the meaning of texts. The National Institute of Child Health and Human Development (2000) identified fluency as one of the five key elements necessary to become a proficient reader in its National Reading Group report. These components include: a) speech, b) phoneme awareness, c) fluency, d) vocabulary, and e) understanding. For many teachers, teaching reading is mainly an exercise of meaning or understanding (Rasinski, 2003a). Focusing on a certain aspect of reading teaching can actually hinder reading development and ultimately lead to long-term reading difficulties for middle school students (Archer, Gleason, and Vachon, 2003; Marston, Deno, Dongil, Diment, and Rogers, 1995).

Still, there may be a shortage of research studies on developing fluency through developing the amount of independent reading; wherein large correlational evidence shows a clear association of the amount students read, their reading fluency, and their text comprehension. Paige (2020) pointed out that although reading fluency has been extensively studied as an independent reading process, it is best considered to be the result of lower level of multiple reading skills than when runs efficiently and simultaneously, resulting in smooth and expressive reading, which is crucial for text understanding. Conversely, students who are struggling with reading are not in a function to interact in reading, and they will want extra guidance and assistance so that they can increase fluency. Research suggests a few techniques, primarily based on repeated readings, to help suffering readers to enhance their fluency.

Until recently, reading fluency had not been a priority in Ethiopian reading instruction. Supporting the idea researchers argue periodic calls for a reexamination of reading fluency would not capture the attention of most reading educators (Zutell \& Rasinsiki, 1991). That may have been due to many educators perceived fluency as nothing more than reading fast or with good oral expression (Rasinski, 2006). Neither of those regarded even remotely related to the well-accepted purpose of reading comprehension. Things begin to change when reading researchers begin to show that reading fluency is a necessary precondition for good reading comprehension (Stanovich, 1994). Most recently, the meta-analysis conducted by the national reading panel (2000) assured reading accuracy as a vital component of the reading process. In the 21 st century, reading fluency has taken its place and reading comprehension as a critical component of active reading instruction. Therefore, the present study contributes the understanding of whether there is a relationship between comprehension-based silent reading fluency measures (accuracy and reading rate) with reading comprehension.

Regarding relationships, the relationship between reading fluency and reading comprehension was linear (Figure 1 and Figure 2). There is a moderate increases in students reading comprehension scores as the reading accuracy increase. The correlation between the students' reading comprehension and their reading fluency (accuracy and reading rate) is positive and statistically significant $(\mathrm{r}=.410, \mathrm{P}<0.001)$ for rate and $(\mathrm{r}=.402, \mathrm{P}<0.001)$ reading accuracy (Table 8). Therefore, the null hypothesis in this study was stated in this study as, "There is not any significant relationship between Ethiopian EFL learners' reading fluency on reading comprehension" is rejected.

The study has also found that students are being deprived of reading speed. The relationship between the speed at which the reader recognizes a word in the text and the composition of the meaning from the text is very poor (Table 4). That is, $78 \%$ of the 100 participants read $25-100$ wpm (they only say 10-40). Correct answer from $100 \%$ comprehension test within a certain period of time). Correlation regression analysis showed a significant association with small effect sizes, but the results cannot be considered simply trivial. The effect size is small when the sample size is small and comfortable, or what Arnold and Feldman (1981) calls social appeal-reaction bias, that is, "hope when answering a specific question or statement. It can happen if the person who does it has to present it very positively." (P.379).In the present study, the students used cognitive resources to comprehend the texts because it was difficult for them to understand the texts automatically. Reading fluency involves not only fast and efficient processing but also the efficient coordination of items. Ethiopian grade 11 students as the study revealed lack fast application of procedures to interpreting without conscious and effortless use of fast reading strategies. This research is consistent with the research conducted by Rasinski (2004) disclosed that fluent readers can accurately and automatically decode words without using their limited attention or conscious cognitive resources. Similarly, Hibert (2015) proved that when students reading skills reached automatic stage, it could be performed without conscious thought about its execution.

However, in this study, it is difficult for students to understand texts that simultaneously learn the structure of vocabulary and grammar. Through this reading, students will be focused on deciphering the meaning of words and understanding their contents, and gradually develop the habit of reading slowly. Such students are exposed to limited comprehension; and become poor readers. Brenner et al., (2010) found that poor readers read less, approach the reading tasks with low level of motivation and interest. Rasinski et al. (2006) investigated the inability of students with limited vocabulary and background knowledge to construct meaning from passages, which led to slow and painstaking reading.

However, in most cases it is mere mechanical decoding that is mistaken for 'fluency', without any attention to comprehension. Samuels et al. (2011) suggest that we must focus on the best means to develop silent reading proficiency, which encompasses a multitude of skills needed to achieve ease and comfort, adequate reading rates, comprehension competency, and vocabulary enhancement in reading. Therefore, developing students studying fluency is fundamental to Ethiopian EFL students to transport from mastering to examine to studying to learn. That is the 
competencies of the scholars to turn out to be unglued from print (deciphering process) and to pay attention at the message of the text (comprehending the writers` conversation in mild in their personal historical past understanding and energetic creation of private meanings) (Rasinski, Lavell, Smith, 2014).

Notion (2007) proposed developing language fluency as one of the four elements of a language course (meaning focused input, meaning focused output, language-focused learning and Fluency). The development of the language flow provides foreign language learners with the opportunity to process and generate languages. It is based on the language skills students have already acquired. Although fluency is important, in recent decades, development in the L1 environment has become noticeable, but this issue has not received much attention in the foreign language environment and there is still a need to develop fluency in FL. The multiple coefficients in the results of this study are 0.416 and the $\mathrm{R}$ square is 0.173 . Therefore, in this sample the predictor variable explained $17.3 \%$ of the variance of the reading comprehension of the dependent variable. Thus, the higher the comprehension-based silent reading accuracy level, the higher their reading comprehension, Beta $=0.42, \mathrm{t}=4.53, \mathrm{p}<0.05$. The standard coefficient of 0.42 is identical to the multiple regression coefficients because there is only one predictor variable besides; the higher degree of reading rate is related to a higher degree of accuracy level. It is also interesting that the correlation between the reading comprehension test and reading fluency measures was moderate and statistically significant.

\section{RECOMMENDATIONS}

The result of this study can generally contribute to students who are not reading at grade level to read fluently, understand vocabulary and comprehend text, the assessments provide parents with a clear indication of how far away their students are from expected levels of performance. Hence, parents can understand this and have an idea of just how much ground their children have to make up to meet grade-level expectations. The investigation will also provide information on what teachers, parents, and students can do to improve their reading and thus, they will become better readers in the target language by learning, reading strategies and increasing their reading rate. More specifically, provides high-level information to teachers about the growth of students' reading fluency and performance over time and enables teachers to make informed, and data-driven teaching decisions to improve teaching and learning. It may support teachers' improvement of their understanding of the principles and concepts of teaching reading. The findings also have implications for curriculum designers. Lastly, this study may serve us an input for researchers who are interested in conducting studies on related topics.

\section{REFERENCES}

[1] Amulya,U. (2019). Mediating Roles of Customer Experience on E-Loyalty. Ushus Journal of Business Management. 18/4, 4154, 0975-3311|https://doi: 10.12725/ujbm.49.4, https://journals.christuniversity

[2] Archer, A. L.,Gleason, M. M., \& Vachon, V. L. (2003). Decoding and fluency: Foundation skills for struggling older readers. Learning Disability Quarterly, 26(2), 89-101. DOI:10.2307/1593592

[3] Arnold,H. J. and Feldman, D. C. (1981). Social Desirability Response Bias in Self-Report Choice Situations. The Academy of Management Journal Vol. 24, No. 2 pp. 377-385.Retrived February 4, 2021 from https://www.jstor.org/stable/255848?seq=1\#metadata_info_tab_contents

[4] Asad,A.A. (2017). Use of web page credibility information in increasing the accuracy of web based question-answering system. Retrieved February 6, 2021 from http://studentsrepo.um.edu.my/7815/9/asad.pdf

[5] Berninger, V. W., Abbott, R. D. ,Olson, P. T, Gould, E. L., Hiramatsu .S, M., Holsinger, McShane .M, Murphy, H., Jennifer N., Boyd A. S., Westhaggen. S. Y. (2010). Applying the Multiple Dimensions of Reading Fluency to Assessment and Instruction. Journal of Psycho-educational Assessment 28(1) 3-18.DOI: 10.1177/0734282909336083.http://jpa.sagepub.com

[6] Bizuwork B. (2018). Assessing factors affecting students' reading comprehension: The case of grade 11 students in Chelenko preparatory school, in the east Harargie zone, Oromia regional state. Retrieved February 24, 2021 from http://localhost:8080/xmlui/handle/123456789/941

[7] Brenner, D., \& Hiebert, E.H. (2010). If I follow the teachers' editions, is not that enough? Analyzing reading volume in six core-reading programs. The Elementary School Journal, 110(3), 347-363.Doi:10.1086/648982

[8] Buzan, T. (2003). The Speed Reading Book. Woodlands: BBC Worldwide Limited.

[9] Cartwright, K. B. (Ed.). (2008). Literacy processes: Cognitive flexibility in learning and teaching. New York: Guilford.

[10] Carver, R. P. (1985). Silent reading rates in grade equivalents. Reading Journal of Reading Behavior, XXI,/.2.Doi. org/10.1080/10862968909547667

[11] Cowan, G. (1998). Statistical Data Analysis. Oxford University Press, Great Clarendon Street, Oxford OX2 6DP. Oxford New York. epdf.pub

[12] Deno, S. (1985). Curriculum-based measurement: The emerging alternative. Exceptional Children, 52, $36-45$. https://journals.sagepub.com/doi/10.1177/001440298505200303

[13] Deribe Gizaw. (2019). English reading difficulties among grade six students in Addis Ababa: Yeka sub-city. Un-published Ph.D. Thesis. Addis Ababa University

[14] Dodi, S. (2013). Improving Students' Reading Rate and Comprehension by Using Timed Repeated Readings. Retrieved March 10, 2021 from http://ejournal.uin-suska.ac.id/index.php/jealt/article/view/72

[15] DuBay, W. E. (ed.). (2006). The Classic Readability Studies .Costa Mesa: Impact Information. Retrieved February 14, 2021 from https://files.eric.ed.gov/fulltext/ED506404

[16] Early Grade Reading Assessment. (2018). USAID reading for Ethiopia's achievement developed monitoring and evaluation (read M\&E). Retrieved March 10, 2021 from https://pdf.usaid.gov/pdf_docs/PA00WQXX 
[17] Flesch, R. (2006). A new Readability Yardstick. In DuBay, W. E (ed.). The Classic Readability Studies. Costa Mesa: Impact Information, 99-112.Doi: 10.1037/h0057532.

[18] Floencio, D.C. (2004).The role of prior background knowledge in the reading comprehension of eel Brazilian college students and American college student. The Pennsylvania State University. Pro -Quest Dissertations Publishing. Retrieved January 10, 2021 from https://www.proquest.com/openview/b9ba0f4ff2f89ee564f43517c9d20786

[19] Foorman, B. R., \& Mehta, P. (2002, November). Definitions of fluency: Conceptual and methodological challenges. PowerPoint presentation at A Focus on Fluency Forum, San Francisco, CA. Retrieved March 10, 2021 from www.prel.org/programs/rel/fluency/Foorman.ppt

[20] Fuchs, L. S., Fuchs, D., Hosp, M. K., \& Jenkins, J. R. (2001). Oral reading fluency as an indicator of reading competence: A theoretical, empirical, and historical analysis. Scientific Studies of Reading, 5, $239-256$. https://doi.org/10.1207/S1532799XSSR0503

[21] Gamse, B. C., Robin, T. J., Horst, Boulay, \& Unlu. (2008). Reading First Impact Study Final Report. National Center for Education Evaluation and Regional Assistance. Retrieved March 11, 2021 from https:/files.eric.ed.gov/fulltext/ED503344.pdf

[22] Gordon, W. (2007). How to read faster and recall more. Spring Hill House, Spring Hill Road, Begbroke, Oxford 0X5 1RX. B The United Kingdom. Retrieved March 11, 2021 from http://www.howtobooks.co.uk

[23] Hamed, G \& Hossein, K. (2011 ed). Modern Journal of Language Teaching Methods. Retrieved March 11, 2021 from http://mjltm.org/article-1-29-en.pdf

[24] Hiebert, E. H. (2015). Teaching Stamina and Silent Reading in the Digital-Global Age. Text Project University of California, Santa Cruz

[25] Hiebert, E.H., \& Daniel, M. (2018). Comprehension and rate during silent reading: Why do some students do poorly? Reading and Writing. DO - 10.1007/s11145-018-9917-7

[26] Hiebert, E. H., \& Daniel, M. (2019). Comprehension and rate during silent reading: Why do some students do poorly? Reading and Writing, 32(7), 1795-1818. DOI:10.1007/s11145-018-9917-7

[27] Hiebert,E,H., \& Trainin,G. (2019). Patterns of Silent Reading Rate and Comprehension as a Function of Developmental Status, Genre, and Text Position. Retrieved March $12, \quad 2021$ from https://www.tandfonline.com/doi/abs/10.1080/02702711.2019.1673602?journalCode=urpy20

[28] Ho, R. (2006). Hand book of uni-variate and multivariate data analysis and interpretation with SPSS. Taylor \& Francis Group,6000 Broken Sound Parkway NW, Suite 300 ,Boca Raton, FL 33487-2742

[29] Huey, E. B. (1908). The psychology and pedagogy of reading. New York, NY: The Macmillan Company.

[30] Huffman, J. (2021). Development of Reading Fluency during an Extensive Reading Course Incorporating Reading Fluency Tasks. Retrieved March 12, 2021 from http://hdl.handle.net/20.500.12613/6516

[31] Irawan,A. (2013). Teaching vocabulary with the theme "fruits" trough word search puzzle to the seventh grade students of the state junior high school 16 of Palembang. Retrieved March 10, 2021 from http://jengkolpintar.blogspot.com

[32] Jenkins, J., Fuchs, L., van den Broek, P., Espin, C., \& Deno, S. (2003). Sources of individual differences in reading comprehension and reading fluency. Journal of Educational Psychology, 95, 719-729. DOI:10.1037/0022-0663.95.4.719

[33] Jenkins. J, Schulze, M, Marti, A, Harbaugh, A. G. (2017). Curriculum-Based Measurement of Reading Growth: Weekly Versus Intermittent Progress Monitoring https://journals.sagepub.com/doi/10.1177/0014402917708216

[34] Kim, Y.-S., Petscher, Y., Schatschneider, C., \& Foorman, B. (2010). Does the growth rate in oral reading fluency matter for reading comprehension? Journal of Educational Psychology, 102, 652-667. DOI:10.1037/a0019643

[35] Konstant, T. (2003). Speed Reading. London: Hodder Headline Ltd.

[36] Krejcie, R.V. \& Morgan, D.W. (1970). Determining sample size for research activities. Educational and psychological $\begin{array}{llllll}\text { measurement, } & 30: & \text { 607-610. } & \text { Retrieved } & \text { March } & \text { 10, }\end{array}$ https://home.kku.ac.th/sompong/guest_speaker/KrejcieandMorgan_article.pdf

[37] Kuhn,M.,Young,C.\& Rasinsiki. (2018). Best practices in reading fluency instruction. Retrieved March 10, 2021 from https://www.researchgate.net/publication/336348968

[38] Kumar, R. (2006). Research methodology: A step-by-step guide for beginners. London: SAGE Publishers Ltd.

[39] Kwiatkowska-W.B. (2012). Understanding reading comprehension performance in high school students. Retrieved March 13, 2021 from https://qspace.library.queensu.ca/bitstream/handle/1974/7395/ Ph.D..pdf ? sequence=1

[40] La Berge, D., \& Samuels, S. (1974). Toward a theory of automatic information processing in reading. Cognitive Psychology, 6, 293-323.https://doi.org/10.1016/0010-0285 (74)90015-2

[41] Linda,W., Michele, W, Betty, R.V., Avory F. (2000). National Institutes of Child Health and Human Development Neonatal Research network. Validation of the National Institutes of Health consensus definition of bronchi pulmonary dysplasia. American Academy of Pediatrics, PEDIATRICS 116(6):1353-60, DOI:10.1542/peds.2005-0249

[42] Marston, D., Deno, S. L., Dongil, K., Diment, K., \& Rogers, D. (1995). Comparison of reading intervention approaches for students with mild disabilities. Exceptional Children, 62, 20-38.Doi/ pod/10.1177/001440299506200103

[43] Mertens, D. M. (2018). Mixed methods design in evaluation. Thousand Oaks, CA: SAGE

[44] Ming,K \& Dukes,C. (2008). Fluency: A Necessary Ingredient in Comprehensive Reading Instruction in Inclusive Classrooms. Teaching Exceptional Children Plus Volume 4, (4). Retrieved March 13, 2021 from http://escholarship.bc.edu/education/tecplus/vol4/iss4/art6

[45] Ministry of Education. (2018-30). Ethiopian education development roadmap: an integrated executive summary: Draft for discussion. Addis Ababa, Ministry of Education, Education Strategy Center (ESC) Retrieved March 13, 2021 from https://planipolis.iiep.unesco.org/en/2018/

[46] Ministry of Education. (2003). English for Ethiopia. Students' textbook Grade 11

[47] Ministry of Education. (2003). English for Ethiopia. Teacher Guide Grade 11

[48] MOE. (2013). Education Statistics Annual Abstract 2012/2013. Ministry of Education, Addis Ababa, Ethiopia

[49] Nation, I.S.P. \& Beglar, D. (2007). A vocabulary size test. The Language Teacher 31, 7: 9-13. Retrieved March 14, 2021 from https://jalt-publications.org/files/pdf/the_language_teacher/07_2007tlt 
[50] Nation, I.S.P. (2008). Teaching ESL/EFL Reading and Writing. New York. DOI:10.4324/9780203891704

[51] Nation, I.S.P. \& Newton, J. (2009). Teaching ESLEFL Listening and Speaking. New York: Rutledge. DOI:10.1016/j.system.2009.11.002

[52] National Center for Education Statistics. (2017). National Assessment of Educational Progress (NAEP): 1992-2017 reading assessments. Washington, DC: Institute of Education Sciences, U.S. Department of Education. Retrieved March 13, 2021 from https://www.nationsreportcard.gov/reading_2017/

[53] National Reading Panel. (2000). Report of the National Reading Panel: Teaching children to read. Report of the subgroups. Washington, DC: U.S. Department of Health and Human Services, National Institutes of Health.

[54] Nichols,W. D., Rupley, W. H., \& Blair, T. (2005). Re-conceptualizing Phonics Instruction from a Constructivist View. Preconvention institute \# 16 papers presented at the International Reading Associations annual conference in San Antonio, TX.

[55] Oguttu, W. (2015). Determinants of students' academic performance in private secondary schools in Wakiso district. Unpublished Masters Dissertation. Makerere University. Retrieved March 13, 2021 from http://dspace.mak.ac.ug/bit stream/handle/10570/6020

[56] Paige ,D.D., Rasinski, T, Lavell. T. M, and Smith, G. S. (2014). Interpreting the Relationships among Prosody, Automaticity, Accuracy, and Silent Reading Comprehension in Secondary Students. Journal of Literacy Research 46(2) 123-156. DOI: 10.1177/1086296X14535170 jlr sage pub.com.

[57] Paige,D.D. (2020). Reading Fluency: A Brief History, the Importance of Supporting Processes, and the Role of Assessment. Retrieved March 13, 2021 from https: //files.eric.ed.gov/ full text/ED607625

[58] Pikulski, J., \& Chard, D. (2005). Fluency: Bridge between decoding and reading comprehension. The Reading Teacher, 58(6), 510-519. Retrieved March 13, 2021 from https: //www.jstor.org/stable/20205516?

[59] Rasinski, T. (2003a). Fluency is Fundamental. Instructor, 113(4), 16-17, 19-20. Retrieved March 14,2021 from https://www.scholastic.com/teachers/articles/teaching-content/fluency- fundamental/

[60] Rasinski, T. V. (2004). Assessing Reading Fluency. Pacific Resources for Education and Learning, Honolulu, Hawaii.www.prel.org/programs/rel/rel.asp

[61] Rasinski, T. V. (2006). Reading fluency instruction: Moving beyond accuracy, automaticity, and prosody. The Reading Teacher, 59, 704-706.a. DOI:10.1598/RT.59.7.10

[62] Rasinski, T. V. (2010). The fluent reader: Oral and silent reading strategies for building word recognition, fluency, and comprehension (2nd ed.). New York: Scholastic.

[63] Rasinski, T. V., Magpuri, L., T., David, D, D \& Smith, G., S. (2014). Interpreting the Relationships among Prosody, Automaticity, Accuracy, and Silent Reading Comprehension in Secondary Students. Journal of Literacy Research, 46(2) 123156. https://doi.org/10.1177/1086296X14535170

[64] Rasinski, T. V., David, D, D \& Nageldiger, J. (2015). Reading fluency: Neglected, misunderstood, but still critical for practical reading. Retrieved March 14, 2021 from https://www.researchgate.net/publication/281092727

[65] Robert,H. (2006). Hand book of Univar ate and multivariate data analysis with SPSS. Chapman \& Hall/CRC Taylor \& Francis Group 6000 Broken Sound Parkway NW, Suite 300 Boca Raton, FL 33487-2742

[66] Rudolf J. F, William J. W., Ping. (2006). Regression Analysis: Statistical Modeling of a Response Variable. epdf pub regression -analysis-second-edition.

[67] Samuels, S.J. (1987). Information Processing Abilities and Reading. https://journals.sagepub.com/ Doi/10.1177/002221948702000104

[68] Samuels, S. J. (2002). Reading fluency: Its development and assessment. In A. E. Farstrup \& S. J. Samuels (Eds.), what research has to say about reading instruction (3rd ed., pp. 166-183). Newark, DE: International Reading Association

[69] Samuels, S. J., \& Flor, R. F. (2006). The importance of automaticity for developing expertise in reading. Reading \& Writing Quarterly: Overcoming Learning Difficulties, 13 (2):pp.107-121. https://doi.org/10.1080/1057356970130202

[70] Samuels, S. J \& Rasinski,T. (2011). Reading Fluency: What It Is and What It Is Not. Retrieved February 5, 2021 from https://www.researchgate.net/publication/300042083

[71] San,T.O. (2011). An Evaluation Forecasting Techniques in Kuala Lumpur Stock Exchange Finance. Int.J.Buss.Mgt.Eco.Res.,2 (6),2011,382-390. ijbmer2011020606.pdf

[72] Schneider, W., \& Shiffirin J. (2003). Controlled \& automatic processing: Behavior, theory, and biological mechanisms. Cognitive Science, 27, 525-559. https://doi.org/10.1016/S0364-0213 (03)00011-9

[73] Schreiber, P. (1980). On the acquisition of reading fluency. Journal of Reading Behavior, 12, 177-186. Doi $/ 10.1080 / 10862968009547369$

[74] Spiechtig, A. N., Hiebert, E. H., Vorstius, C., Pascoe, J. P., Pearson, P. D., \& Radach, R. (2016). The decline of comprehension-based silent reading efficiency in the United States: A comparison of current data with performance in 1960.Reading Research Quarterly, 51(2), 239-259.DOI:10.1002/rrq.137

[75] Stanovich, K. E. (1994). Annotation: does dyslexia exist? Journal of Child Psychology and Psychiatry, 35 (4), $579-595$. DOI:10.1111/j.1469-7610.1994.tb01208.x

[76] Sutopo,A. (2018). Translation Analysis on Civil Engineering Text Produced by Machine Translator. https://doi.org/10.1051/e3sconf/20183110012

[77] Sutz, R. \& Weverka, P. (2009). Speed Reading for Dummies. Indianapolis: Wiley Publishing, Inc.

[78] Tamene, K. (1992). The preliminary survey of the reading interests of A.A.U. students The Ethiopian Journal of Education, Vol. XIll No.2. Teacher, 42(7), 502-507. Retrieved March 14, 2021 from http://ejol.ethernet.edu.et/index.php/EJE/article/view/495

[79] Tekele, F. M. (2016). A study of independent reading in English as a foreign language (EFL) in Ethiopian schools. Electronic Theses and Dissertations. Retrieved March 14, 2021 from https://uir.unisa.ac.za/handle/10500/22186.

[80] Valencia, S. W., \& Buly, M. R. (2004). Behind test scores: What struggling readers need? The Reading Teacher, 57, $520-531$. Retrieved March 15, 2021 from https://www.jstor.org/stable/2020539

[81] Zutell, J., \& Rasinski, T. V. (1991). Training teachers to attend to their students' reading fluency. Theory into Practice, 30 , 
211-217. Retrieved March 16, 2021 from https://www.jstor.org/stable/1476883

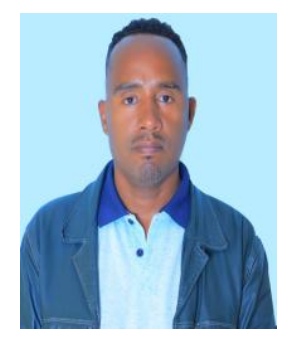

Tadiwos Hambamo is a lecturer at the Department of English Language and literature, Wolaita Sodo University. He received his BA degree in English from Addis Ababa University and his MA degree in TEFL from Wolaita Sodo University. Currently, he is pursuing his PhD in ELT at Wolaita Sodo University. He had taught English language at several public secondary high schools and at Wolaita Sodo University for many years. His main areas of research interest embrace teacher's perceptions and awareness of oral and written feedback and students' reading motivation and silent reading fluency in English language. He published his research works in international scholarly journals such as International Journal of Education and practice, Galaxy: International Multidisciplinary Research Journal, Lambert Academic Publishing and Innovations.

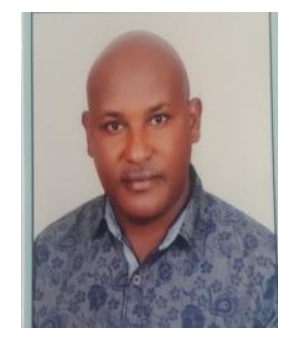

Mebratu Mulatu Bachore $(\mathrm{PhD})$ graduated from Addis Ababa University with B.A in English Language and Literature, MA and PhD in TEFL. Currently, he is an Associate Professor of TEFL at Hawassa University. Before he joined Hawassa University, he taught English Language at Secondary School. He has been teaching different undergraduate and graduate level courses and supervising MA and $\mathrm{PhD}$ candidates. He has more than 14 publications in reputable journals.

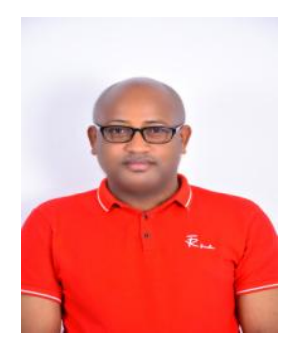

Zeleke Arficho Ayele (PhD) received his B.Ed. degree in English language from Debub University and his $\mathrm{MA}$ and PhD degrees in TEFL from Addis Ababa University. He taught English language at secondary high schools. He has been teaching English at Hawassa University for over a decade. Currently, he is an Associate Professor of TEFL and a Director for Academic Affairs Directorate, Hawassa University. He published over twenty-two original research articles in reputable journals. The scholar is a board member and reviewer for some journals. He is interested in quantitative research designs. 